\title{
Laboratórios virtuais: Um estudo comparativo entre plataformas de aprendizagem para o ensino da química
}

\section{Virtual labs: A comparative study between learning platforms for the teaching of chemistry}

\author{
Cristiane Aquino, Marcelo Teixeira, Maicon Silva, Anderson Santos, Hugo Souza, Cícero Morais, Diogo Homenick \\ Universidade Federal Rural de Pernambuco
}

\begin{abstract}
Resumo
Como proposta para o presente estudo, analisamos os contributos e as limitações dos laboratórios virtuais para o ensino da química, com base em um estudo comparativo. O trabalho qualitativo e empírico descritivo foi desenvolvido no Departamento de Estatística e Informática da Universidade Federal Rural de Pernambuco, e foi desenvolvido no período de maio de 2016 a maio de 2017
\end{abstract}

Palavras chave: Laboratório virtual, Tecnologia educativa, Ambiente virtual, Interatividade.

\begin{abstract}
As a proposal for the present study, we analyze the contributions and limitations of virtual laboratories for the teaching of chemistry, based on a comparative study. The qualitative and empirical descriptive work was developed in the Department of Statistics and Informatics of the Federal Rural University of Pernambuco, and was developed from May 2016 to May 2017.

Keywords: Virtual lab, Educational technology, Virtual environment, Interactivity.
\end{abstract}

\section{Introdução}

Vive-se a era do online, onde as novas compreensões de tempo/espaço conferem um novo status à educação, por meio essencialmente do fenômeno da socialização do conhecimento que ocorre em escala global, num ambiente de partilha de experiências, informações, vivências e aprendizado em rede. Por sua vez, a atual "Sociedade da Informação" configura-se como um estágio natural e evolutivo no desenvolvimento social das pessoas, proveito de um mundo cada vez mais interligado pelos novos meios de comunicação. É o que o Sociólogo Marshall McLuhan denomina de Aldeia Global, escreve Teixeira (2013) no livro "Da educação a distância às plataformas de aprendizagem: sistemas alternativos de educação mediada".

Nesse contexto, a Web pode ser considerada como um dos fatores que impulsionaram a transformação da comunicação de massas, não apenas pela utilização de novas tecnologias, mas que, por meio destas, propiciou a proliferação dos efeitos da globalização em todos os lugares do mundo, e a informação ficou mais acessível para qualquer comunidade que tenha acesso à rede mundial de computadores. Segundo Oliveira (2007), é fundamental pensar a comunicação como um elemento necessário à sociabilidade, entendendo o ato de se comunicar a partir do seu caráter simbólico e intrinsecamente cultural. Deste modo, a inter-relação comunicação/educação traz a perspectiva da crítica à sociedade numa busca constante pela transformação social.

Face ao densenvolvimento tecnológico no decorrer dos anos, do século XX para o século XXI, surge, nos diferentes níveis de ensino, as primeiras experiências de uso de interfaces tecnológicas na educação, os quais acabam por configurar um cenário no qual convivem diferentes iniciativas, desde o ensino básico ao superior e profissionalizante em diferentes partes do mundo, guiados pela colaboração, flexibilidade, baixo custo e interatividade multimídia no espaço virtual. Como uma abordagem sistémica que integra várias funções do processo educativo, os laboratórios virtuais vêm a constituir modos diferenciados de ensinar e aprender, possibilitando a oportunidade de se produzir conhecimento por novas vias, mesclando o presencial e a distância no processo educativo, segundo Aquino e Teixeira (2015).

Assente em tal conjectura, se faz presente a utilização do laboratório virtual como um eficiente recurso tecnológico voltado às aulas teóricas e práticas em instituições de ensino, especialmente na área de química. Aqui, apresentamos um estudo comparativo com laboratórios virtuais para o ensino da química, destacando contributos e limitações em sua utilização por parte de docentes e discentes.

\section{Método}

O presente estudo é de cunho qualitativo e de cariz empírico descritivo, dedicado a analisar Laboratórios Virtuais para o Ensino de Química enquanto tecnologias educacionais contributivas ao processo de ensino, presencial e online. Para tanto, realizamos uma revisão da literatura sobre o tema, selecionamos 
e comparamos cinco laboratórios virtuais de química (estudos de caso), inpirando-se nas pesquisas de Silva (2016), visando elencar pontos positivos e limitações no uso de tais plataformas. Todas as áreas de pesquisa, independente da sua classificação (seja com base nos seus objetivos, procedimentos técnicos ou fontes de informação), exigem uma pesquisa bibliográfica prévia, ponderam Cruz e Ribeiro (2004). Gressler (2004, p.131) comprova a veracidade da afirmativa, pois "para que a uma investigação seja bem sucedida, supõe-se que o pesquisador já tenha conhecimento prévio do assunto. O objetivo da revisão da literatura seria, então, a atualização e integração desse conhecimento. Já no estudo de caso, procuramos apreender o contexto de uma situação e, criativamente, interpretar e descrever a complexidade de um caso concreto, mediante um mergulho profundo e exaustivo em um objeto delimitado, diz Martins (2008). O desenvolvimento da pesquisa decorreu de maio de 2016 a maio de 2017 no laboratório do Departamento de Estatística e Informática da Universidade Federal Rural de Pernambuco (Brasil).

\section{Resultados}

\section{Virtualidade, Recursos Tecnológicos e Educação}

Desde da criação da Web, por Tim Berners-Lee, os meios de comunicação tinham o intuito primordial de fornecer informação aos usuários, aos quais apenas a consumiam e utilizavam os serviços sem autonomia.

Com o passar do tempo, ocorre uma evolução dos serviços para atender a efetiva participação destes usuários no processo de desenvolvimento de aplicações para a Web, emergindo uma revolução social na Internet denominada pelo irlandês Tim O'Reilly de Web 2.0.

A Web tornou-se um espaço virtual de participação, partilha de saberes e envolvimento das pessoas no processo de criação. Processo este conceituado por Lévy (1999) como a "inteligência coletiva". Desse modo, a Web passou a adquirir um carácter social, constituindo-se em uma rede formada de pessoas colaborativas e influentes no processo de geração, distribuição e organização da informação (Silva, 2007).

Consequência da globalização e da expansão tecnológica, a multiculturalidade, daí resultante, prescreveu uma nova estrutura social, composta por pessoas e empresas de diversos segmentos, norteados por interações, colaborações, troca de saberes no recém adulto "universo virtual". Sobre o assunto, Paul Virilio (1993) citado em Teixeira (2013), alerta para a dispersão temporal e perda da noção de realidade no ciberespaço, uma atopia para os nativos digitais, imersos num oceano de informações inesgotáveis. Em compensação, escreve Howe (2009) que, criados com base na mídia social e sempre conectados a Internet, os nativos digitais se concentram em vários projetos simultaneamente, colaboram tranquila e espontaneamente com pessoas que nunca viram na vida e, o mais importante, criam mídias com a mesma avidez com que as gerações anteriores consumiam. "É uma comunidade crowdsourcing, uma população perfeitamente adaptada a um futuro em que as comunidades online irão suplantar a corporação convencional" (idem, p.10). Desse modo, é quase impossível condicionar os nativos digitais para uma vida "menos virtual ou tecnológica", pelo fato já terem nascido numa sociedade da informação e do conhecimento.

No cenário da Educação, e mais precisamente, no contexto da educação à distância, as possibilidades de aprendizagem através das interfaces da Web 2.0 surgem como uma resposta à tradicional estrutura estática da Internet. Daí, Lévy (1999), o universo World Wide Web favorece a inteligência coletiva no domínio educativo e na aprendizagem cooperativa, produzindo uma cibercultura na sociedade da informação. Castells (2009), sobre o assunto, afirma ainda que a Web permitiu a grupos de interesse e a projetos na rede ultrapassarem problemas de tempo/custo associados à caótica informação pré$w w w$, pois, nesta base, grupos, indivíduos $\mathrm{e}$ organizações puderam interagir significativamente com o que se tornou, literalmente, uma vasta rede mundial de comunicação interativa e individualizada.

Noutro sentido, Sartori e Roesler (2003) explicam que, num primeiro momento, as pessoas têm o sentimento de pertencer a algo e, num segundo momento, pelas relações comunicacionais estabelecidas no espaço virtual, realiza-se um processo de assimilação, apropriação e partilha dos sentidos e saberes. O senso de pertencer é possível em virtude de uma territorialidade simbólica, manifestada nas ações executadas à distância. Os utilizadores participam, emitem opiniões, constróem novos significados, tecem uma rede de cooperação proporcionada por um processo de comunicação bidirecional. Para a educação, Teixeira (2012) defende que a Web potencializou o surgimento de comunidades virtuais de aprendizagem, abrangendo um vasto conjunto de aplicações e a disponibilização de conteúdos na Internet.

Desse modo, o ciberespaço tem possibilitado o desenvolvimento de ambientes virtuais de aprendizagem voltados para a utilização de softwares de interação e da própria Internet como interface pedagógica, potencialmente capaz de diminuir as distâncias geográficas e de aumentar a interação entre pares discentes e docentes, sobretudo, os que atuam na modalidade de ensino a distância.

Se forem observados o projeto educativo e a facilitação do ensino, esses espaços virtuais podem-se transformar num local de experiências de aprendizagem colaborativa rica e satisfatória, em um processo coletivo e interativo de construção do conhecimento do qual os alunos participam ativamente, formulando ideias que suscitam reações e respostas de outros pares, consideram Harasim et al. (2005).

As instituições de ensino podem fazer uso das tecnologias educacionais (como os laboratórios virtuais) como complemento das aulas ministradas. Por isso, o grande desafio dos educadores é de propor 
tecnologias educativas que venham a ser utilizadas como didática pedagógica, com intuito de dinamizar as aulas e estimular participação discente dentro e fora dos espaços escolares.

\section{Laboratórios Virtuais}

Em consideração a uma educação tecnológica, destacamos que na perspectiva construtivista de aprendizagem, os ambientes virtuais de aprendizagem, assim como a utilização de diferentes tecnologias educativas, implicam em propiciar ao aluno múltiplas representações da realidade, apresentando tarefas contextualizadas e promovendo uma análise de questões-problema mais próximas da realidade. Inúmeras são as atividades nesse sentido que um ambiente virtual de ensino pode oferecer tanto como recurso para o professor, quanto para o aluno, ao qual irá realizar essas atividades por meio de um computador, tablet, smartphone, conectado a rede, nas palavras de Silva (2016).

Neste contexto, constatamos que os laboratórios virtuais (softwares educativos que podem estar disponibilizados na Web e/ou instalados em computadores, tablets, smartphones, etc., permitem realizar experimentos realistas e sofisticados com os principais recursos de um laboratório físico. Aqui, os alunos têm acesso a um ambiente virtual de aprendizagem onde podem fazer escolhas como se estivessem em um laboratório tradicional, simulando e observando todas as reações com a mesma segurança e precisão.

Daí, os laboratórios virtuais de Ensino de Ciências (voltados ao ensino da física, química, biologia e a matemática, por exemplo) visam, em sua maioria, a divulgação científica ou até mesmo a divulgação de laboratórios reais e seus recursos, até mesmo porque nos dias atuais cada vez mais exige-se a atualização das práticas docentes de acordo com as habilidades dos alunos. Sendo assim, os docentes se veem obrigados a dominar as inovações tecnológicas para a realização de suas aulas, e assim acompanharem o ritmo interativo do cenário virtual, considera Silva (2016). São, de fato, ambientes virtuais que permitem o uso de uma grande variedade de linguagens e recursos multimídia a disposição de educadores e educandos.

$\mathrm{Na}$ opinião desta autora, para a química, o laboratório tem um papel essencial e as pesquisas têm revelado a sua importância no engajamento dos estudantes no processo de investigação, articulando o trabalho experimental à resolução de problemas, podendo ser muito eficaz para a aprendizagem de conceitos, procedimentos e fixação de conteúdos lecionados em sala de aula presencial. Seguindo este raciocínio, Lopes (2008) sugere que no âmbito do ensino de química uma alternativa para tornar as aulas mais atrativas e dinâmicas, seriam a utilização do computador fazendo uso de programas através de um laboratório virtual, podendo realizar diversos experimentos. Essa necessidade de diversificar métodos de ensino e de aprendizagem pode minimizar a falta de material nas atividades experimentais, visivelmente presente nas Ciências Naturais. Inclusive, Silva (2010) afirma que a atividade experimental possibilita a introdução de conteúdos a partir de seus aspectos macroscópicos, por meio de análise qualitativa de fenômenos. Porém, a maior parte das escolas de ensino médio e superior brasileiras não possuem infraestrutura laboratorial necessária para a realização de experimentos práticos.

Entre outras contribuições para o processo educativo, os laboratórios virtuais de química possibilitam simular determinados conteúdos abordados na disciplina escolar/universitária, estimulando o trabalho colaborativo em grupo em busca da resolução de problemas e, consequentemente, uma maior dinamização das aulas.

Por outro lado, existem diferentes desafios para a utilização de laboratórios virtuais de química que não se limitam apenas a falta de conhecimento do educador, mas também da facilidade de uso e de navegação no ambiente virtual de aprendizagem (usabilidade), das interfaces tecnológicas disponíveis (adequadas a perspectiva do educador), da teoria de aprendizagem subjacente do AVA para a prática pedagógica, a acessibilidade para portadores de deficiência, entre outros.

É a partir de tal realidade que realizamos uma análise de cinco laboratórios virtuais de química, inspirando-se no guia de análise de laboratórios virtuais de Silva (2016).

\section{Análise de Laboratórios Virtuais: Estudo Comparativo}

Diante dos critérios para a escolha dos laboratórios virtuais de química (mencionados em epígrafe), selecionamos cinco laboratórios (de caráter público e privado), que atendem a determinados aspectos, como a) Usabilidade / Navegabilidade; b) Acessibilidade; c) Interfaces Tecnológicas; Teoria(s) de Aprendizagem Subjacentes; d) atividades didáticas propostas.

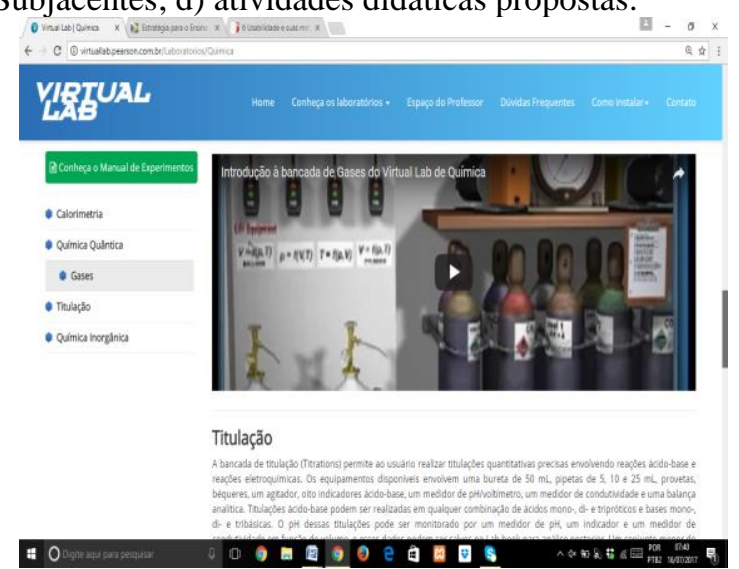

Figura 1. Website do Virtual Lab Química Fonte:http://virtuallab.pearson.com.br/Laboratorios/Quimica

a) Usabilidade/ Navegabilidade: Ambiente virtual de fácil utilização e assimilação por parte do usuário, com um design virtual agradável e eficiente quanto à possibilidade de realizar uma atividade e memorizá-la.

b) Acessibilidade: Não foi reconhecida. 
c) Interfaces Tecnológicas: As opções que existem limitam-se a interações síncronas.

d) Teoria(s) de Aprendizagem Subjacentes: A teoria de aprendizagem subjacente indicada pela arquitetura do design instrucional que podemos observar é a Cognitivista, apesar da dificuldade de concepção clara desta teoria com base na resolução de problemas.

e) Atividades Didáticas Propostas: O ambiente virtual de aprendizagem se molda de acordo com as perspectivas didáticas do educador.

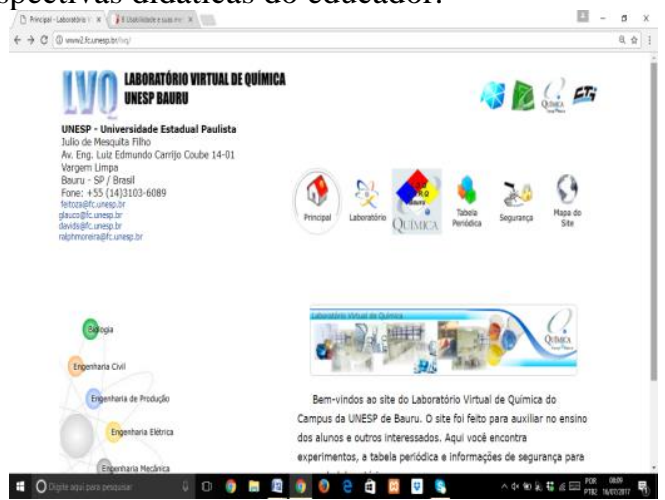

Figura 2. Website do Laboratório Virtual de Química UNESP Bauru

Fonte: http://www2.fc.unesp.br/lvq/

a) Usabilidade/ Navegabilidade: Ambiente virtual de fácil utilização (com aspecto rudimentar) e assimilação por parte do usuário, com um design virtual agradável e eficiente quanto à possibilidade de realizar uma atividade e memorizá-la.

b) Acessibilidade: Não foi reconhecida.

c) Interfaces Tecnológicas: A opção que existe limita-se a interação síncrona por e-mail.

d) Teoria(s) de Aprendizagem Subjacentes: A teoria de aprendizagem subjacente indicada pela arquitetura do design instrucional que podemos observar é a Behaviorista, apesar da dificuldade de concepção clara desta teoria com base na resolução de problemas.

e) Atividades Didáticas Propostas: Existe limitação quanto ao leque de atividades propostas para o ensino da química.

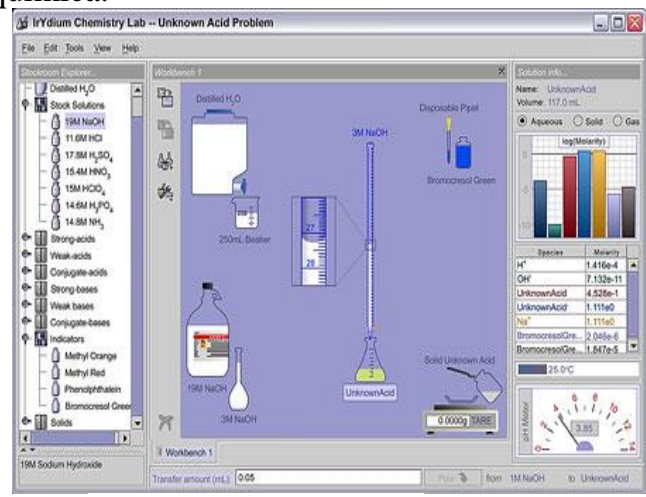

Figura 3. IrYdium Chemistry Lab

Fonte: www.educational-freeware.com/online/chemistrylab.aspx

a) Usabilidadel Navegabilidade: Ambiente virtual de excelente usabilidade, contudo, exige conhecimentos precedentes por parte do usuário.

b) Acessibilidade: Não foi reconhecida. c) Interfaces Tecnológicas: A opção que existe limita-se a interação síncrona por e-mail.

d) Teoria(s) de Aprendizagem Subjacentes: A teoria de aprendizagem subjacente indicada pela arquitetura do design instrucional que podemos observar é a Behaviorista, apesar da dificuldade de concepção clara desta teoria com base na resolução de problemas.

e) Atividades Didáticas Propostas: Existem muitas opções de atividades propostas para o ensino da química (fóruns, tutoriais, ensaios, etc.).

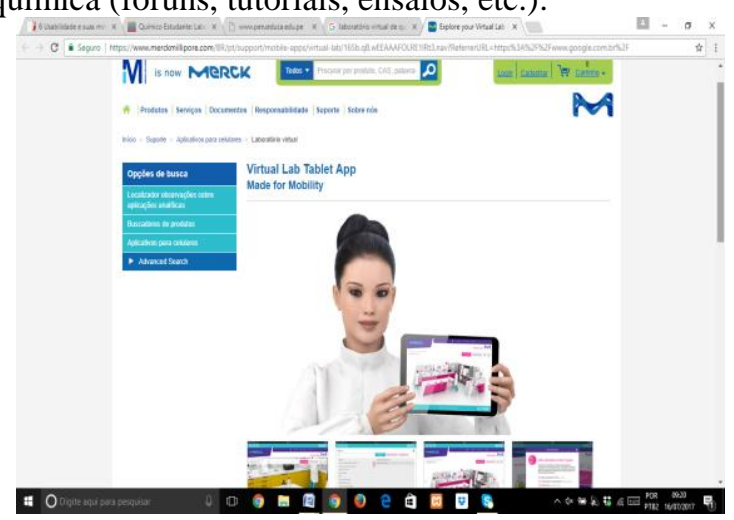

Figura 4. Website Merk

Fonte: https://www.merckmillipore.com

a) Usabilidade/ Navegabilidade: Ambiente virtual de excelente usabilidade, contudo, exige conhecimentos precedentes por parte do usuário.

b) Acessibilidade: Não foi reconhecida.

c) Interfaces Tecnológicas: Existem opções de interação síncrona e assíncrona.

d) Teoria(s) de Aprendizagem Subjacentes: A teoria de aprendizagem subjacente indicada pela arquitetura do design instrucional que podemos observar é a Construtivista, apesar da dificuldade de concepção clara desta teoria com base na resolução de problemas.

e) Atividades Didáticas Propostas: Existem muitas opções de atividades propostas para o ensino da química.

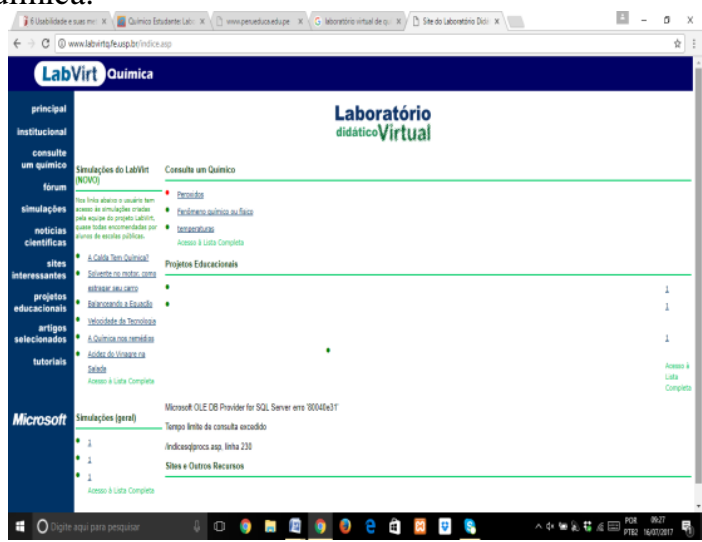

Figura 5. Laboratório Didático Virtual Fonte: http://www.labvirtq.fe.usp.br/indice.asp

a) Usabilidade/ Navegabilidade: Ambiente virtual de excelente usabilidade, contudo, exige conhecimentos precedentes por parte do usuário.

b) Acessibilidade: Não foi reconhecida.

c) Interfaces Tecnológicas: Existem opções de interação síncrona. 
d) Teoria(s) de Aprendizagem Subjacentes: A teoria de aprendizagem subjacente indicada pela arquitetura do design instrucional que podemos observar é a Construtivista, apesar da dificuldade de concepção clara desta teoria com base na resolução de problemas.

e) Atividades Didáticas Propostas: Existem muitas opções de atividades propostas para o ensino da química (fóruns, tutoriais, ensaios, etc.).

\section{Discussão dos Resultados}

No estudo comparativo entre os cinco laboratórios de química investigados, constatamos que não existe preocupação quanto à acessibilidade e a integração de portadores de deficiências motoras e mentais, o que se configura como um aspecto negativo, tanto quanto a falta de claridade sobre a teoria de aprendizagem subjacente indicada pela arquitetura do design instrucional, o que gera um impacto direto e indireto nas atividades didáticas propostas pelo educado, e a ausência de incentivo a interatividade síncrona entre a comunidade discente (e seus pares) e docente. Por outro lado, os laboratórios analisados são de fácil utilização e assimilação por parte do usuário, com um design virtual agradável e eficiente quanto à possibilidade de realizar uma atividade e memorizá-la. Já as opções de atividades didáticas não existem uma utilização das interfaces da Web 2.0 quanto as suas potencialidades, pois as opções que se fazem presentes limitam-se a postagem de informações, em sua grande maioria. Entretanto, o laboratório pode ser customizado consoante as exigências da instituição de ensino/professor para a empresa responsável em desenvolver o ambiente virtual de aprendizagem. Nem tanto quando observamos os laboratórios de instituições públicas de ensino, como constatamos na pesquisa realizada.

\section{Conclusão}

Existe, na verdade, uma tendência ao didatismo, para tornar um conceito assimilável, chegando ao abstrato a partir do concreto, pelo estabelecimento de uma continuidade com o senso comum. A razão disto pode estar no fato de os alunos se encontrarem mais perto dos conhecimentos cotidianos, de tal modo que seus problemas, quando colocados, não são os da ciência. Por isso, se faz necessário construir uma ponte entre a ciência e o conhecimento cotidiano, defende Claxton (1991).

Justamente, é deste modo que os laboratórios virtuais de química, presentes ou não na Internet, precisam ser idealizados, desenvolvidos e utilizados em sala de aula, propondo atividades no ambiente virtual com base em situações concretas, vivenciadas pelos aprendentes e transpostas para o ambiente virtual de aprendizagem. Mas para tanto, é necessário, ao menos, uma eficiente usabilidade e se existe acessibilidade naquele, ancorado em fácil navegabilidade, interfaces tecnológicas intuitivas e sem grandes dificuldades de uso, e teoria(s) de aprendizagem adequada $(\mathrm{s})$ à proposta didática do professor.

O que se evidencia é uma tendência a valorizar um processo de ensino e aprendizagem em laboratórios de química como "espelhos" da sala de aula presencial. Ou seja, é preciso um maior envolvimento da comunidade docente na utilização de laboratórios virtuais para reverter em prática os conteúdos teóricos lecionados em sala de aula. De igual modo, os cursos de formação também são necessários para que esses ambientes sejam utilizados com eficiência e seus recursos sejam corretamente sugeridos para o processo educativo.

\section{Referencias}

Aquino, C. D.; Teixeira, M. M. (2015). Comunicação midiática, hipertexto e interação. Raleigh: Lulu Publish.

Castells, M. (2009). Communication power. New York: Oxford University Press.

Claxton, G. (1991). Educar mentes curiosas. El reto de la ciencia en la escuela. Madrid: Visor.

Cruz, C.; Ribeiro, U. (2004). Metodologia científica teoria e prática. Rio de Janeiro: Axcel Books.

Harasim et al. Redes de aprendizagem: um guia para ensino e aprendizagem on-line. São Paulo: Editora Senac, 2005, p. 337- 346.

Howe, J. (2009). O poder das multidões - por que a força da coletividade está remodelando o futuro dos negócios. Rio de Janeiro: Elsevier.

Lopes, P. C. C. T. (2004). Contributo do Laboratório Químico Virtual para Aprendizagens no Laboratório Químico Real. Universidade de Trás-os-Montes e Alto Douro. Dissertação de mestrado. Vila Real: Universidade de Trás-osMontes e Alto Douro. 
Lévy, P. (1999). Collective intelligence: Mankind's emerging world in Cyberspace. Cambridge: Helix Books.

Oliveira, K. (2007). O potencial educativo do rádio $e$ da comunicação popular. Actas do $5^{\circ}$ Congresso da Associação Portuguesa de Ciências da Comunicação, realizado em Braga, de 6 a 8 de Setembro de 2007, pp.1883-1907.

Gressler, L. (2004). Introdução à pesquisa - projetos e relatórios. São Paulo: Loyola.

Santori, A.; Roesler, J. (2003). Comunidades virtuais de aprendizagem: espaços de desenvolvimento de sociedades, comunicação e cultura. Comunicação apresentada no II Simpósio da Faculdade de Comunicação e Filosofia da Pontifícia Universidade Católica de São Paulo, realizado em São Paulo, de 7 a 8 de Novembro de 2003. Disponível em: http://www.pucsp.br/tead/n1a/artigos\%20pdf/artigo 1.pdf (acedido em 2 de Junho de 2017).

Silva, R. (2016). Breve panorama sobre o uso das tecnologias e laboratórios virtuais no ensino de química do ensino médio das séries regulares em Pernambuco. (Dissertação de Mestrado). Recife: Programa de Pós-Graduação em Ensino das Ciências da Universidade Federal Rural de Pernambuco.

Silva, M. M. (2010). Laboratório virtual de química: Blender 3D auxiliando no ensino da química. In: Simpósio Brasileiro de Educação, Natal. Disponível:

http://publicacoes.unigranrio.br/index.php/pecm/arti cle/download/2227. Acesso em 04 de Julho de 2017.

Teixeira, M. M. (2013). Da educação a distância às plataformas de e-learning: sistemas alternativos de educação mediada. Munique: Grin Verlag.

Teixeira, M. M. (2012). As faces da comunicação. Munique: Grin Verlag.

\section{Agradecimentos}

Grupo de Pesquisa Tecnologias Colaborativas em Saúde (TECNES) - Universidade Federal Rural de Pernambuco. 